\title{
Inter-agency collaboration in the closure of psychiatric hospitals
}

\author{
ANDREW Nocon, Research Associate, Centre for Primary Care Research, University of \\ Manchester M14 5NP; and DyLAN TomLInson, Research Sociologist, Team for the \\ Assessment of Psychiatric Services, Friern Hospital, London N11
}

The needs of people with mental health problems transcend agency boundaries. Service-planning, however, has often been carried out within the confines of individual agencies. Although inter-agency collaboration has been an integral part of official policy since 1974 (DHSS, 1974), joint planning has often been limited to the allocation of centrallyearmarked joint finance (DHSS, 1976). In the ten years following the introduction of joint planning, few authorities prepared, let alone attempted to implement, any broader joint strategies.

The nature of joint planning began to change following the launch of the Government's Care in the Community initiative in 1983 (DHSS, 1983). This enabled health authorities to transfer money to local authorities or voluntary organisations in respect of patients discharged from long-stay hospitals. It thereby helped to overcome the financial obstacles that had previously bedevilled the transfer of longstay patients to community-based care. It also paved the way for the further rundown of large psychiatric and mental handicap hospitals.

Care in the Community explicitly calls for interagency planning. Such planning, though, can be fraught with difficulties (Audit Commission, 1986; Booth, 1981; Glennester et al, 1983; Rathwell, 1987). In this paper we examine the nature of the joint planning carried out in relation to the closure of three large psychiatric hospitals in two regions of England.

It needs to be pointed out that joint planning itself is an administrative process that is neutral in respect of the quality of eventual outcomes. For the patients whose lifestyles depend on that process, the quality and appropriateness of the resulting provision are the principal criteria by which the process should be judged. However, if appropriate outcomes are to have any chance of being realised, it is essential that any problems within the process itself should be recognised and resolved. Our concern here will thus be with the joint planning process itself.

\section{Initiating the joint planning process}

The reasons for closure were similar in the two regions. Local mental health services were being developed within individual districts and fewer beds were needed at the large psychiatric hospitals. The creation of new district health authorities (DHAs) in 1982 itself acted as a stimulus for closure: the hospitals had large catchment areas which often bore little relation to DHA boundaries, while DHAs were only concerned with services for their own discrete communities.

In South Region it was the regional health authority (RHA) which decided that two hospitals should be closed. Following a period of consultation with the relevant DHAs, two hospitals were selected and the rundown process began. In North Region, the initiative came principally from the DHA responsible for managing the hospital, though the RHA gave its approval to the closure plan.

The joint planning process also began differently in the two regions. The RHA in South Region decreed that local authorities (LAs) were to be actively involved in the relocation of long-stay patients into the community. In order to facilitate this process, it established a revenue policy based on the 'dowry' principle, whereby a given amount of money would be transferred with every long-stay patient who moved out of hospital. At the same time, considerable flexibility was built into the policy so that patients' different needs could be catered for at an individual level. Substantial capital was also set aside from the RHA's ten-year programme to assist the closure process.

In North Region, the host DHA's reprovision plans were based on DHSS norms for mental illness services: this entailed the setting of target levels of district general hospital (DGH) beds and day places per hundred thousand head of population. However, the DHA found that these normative levels would not generate sufficient beds for all current long-stay patients. Many of those patients did not require medical or nursing care and the LA was approached to provide alternative facilities. The RHA, for its part, agreed to provide bridging finance.

Differences of approach subsequently became apparent between the DHAs in the two regions. One of the three DHAs most involved in the closures in South Region agreed on a division of labour with its respective LA: the DHA would cater for former long-stay patients while the LA would concern 
itself with the development of other (non-medical) community mental health services.

The other two DHAs experienced much greater conflict in their relations with LAs. The second district initially proposed that it would provide DGH beds for all its current long-stay patients. Following LA pressure, it agreed that accommodation should be phased in by the LA and voluntary sector to replace at least part of this provision. In the third district, the DHA envisaged the redevelopment of part of the existing hospital site and the provision of nursing-home places for some elderly and long-stay patients. The LA and voluntary sector agreed to provide some additional accommodation. While a change in LA leadership led to increased questioning of the DHA's leading role in reprovision, the DHA's own reprovision plans remained largely intact.

In North Region, the LA (which was coterminous with both health districts) rejected the DHA's call to assess patients who had been identified for transfer to LA provision. Instead, it established a joint forum whose task was to examine the field of community care in general. The LA wanted to consider all current long-stay patients for non-NHS community provision. In practice, though, the agencies focused their joint attention on the less dependent patients and the DHAs proceeded with their own normsbased reprovision plans.

\section{Problems encountered}

The above account masks the many difficulties and conflicts that the agencies encountered in the early stages of joint work. They mistrusted each others motives, they held conflicting views about the overall shape and philosophy of the services required, resources were largely tied up in existing services and it was not clear (despite promises of bridging finance) how they might be released, and the agencies were unsure how the joint planning machinery might be harnessed to their own internal decision-making systems. Within individual agencies, managers faced opposition from medical staff and trade union groups who maintained that closure plans elsewhere in the country had resulted in former patients sleeping on park benches.

In the joint planning forums themselves, one of the main problems concerned the precise scope of the joint exercise. While the LAs directed discussion towards a comprehensive mental health service, DHAs were concerned first with a normative level of service and, secondly, with 'limited life' provisions that would meet the needs of current long-stay patients but not form part of a longer-term pattern of services. Conflict between LAs and DHAs over the aims of joint discussions was particularly evident in South Region, where the RHA supported LA involvement in the planning process. In North Region, the DHAs made it clear that resources were limited and that the debate thereby had to be restricted to the 'residual' patients only. Given the DHAs' control of the resources, the LA had no option but to accept this position.

Another major problem concerned finance, especially in North Region. In South Region, the revenue funding issue was clarified at an early stage: although it proved contentious in practice, it did at least provide a basis for the allocation of funds.

In North Region, though, the RHA's initial bridging fund was soon exhausted and the RHA told the DHAs they would have to finance new developments from their own savings. In these circumstances, the DHAs were particularly drawn to low-cost schemes and proposals involving the injection of external finance, for instance from the Housing Corporation. They also sought to pressurise the LA to contribute resources, on the grounds that it had failed to make adequate provision in the past and had relied, instead, on the DHAs to care for people with mental health problems. In the course of negotiations, the LA did provide two buildings for use as rehabilitation hostels and agreed, under pressure, to allocate some cash for their conversion.

However, the agencies' respective financial responsibilities were not clearly set out. While the DHAs in North Region accepted the LA's price for places in aged persons' homes, for example, they rejected another LA proposal which included management and social work elements in the costings.

Practical problems concerning the purchase and preparation of buildings were coniderable in both regions, particularly in the early stages and before the agencies developed a clear approach to the issues involved. Costs typically rose as implementation progressed and delays occurred as additional problems became evident. Agencies were often tempted to abandon projects: only a considerable degree of flexibility and a determination to achieve political goals enabled them to persevere.

\section{Findings}

Although the various DHAs adopted different approaches to the joint planning task, the results of their endeavours were markedly similar.

In the two districts of South Region where most conflict took place, the DHAs' own large-scale capital schemes began to drop into the background as pressure mounted for more immediate means of relocating patients. The same pressure led to a shift away from a rational approach to reprovision planning as a whole and towards a smaller-scale, more opportun istic approach. Plans were drawn up for units within LA aged persons' homes, adult fostering places, and a variety of housing association and other voluntary sector schemes based on hostels and group homes. 
The two DHAs between them prepared plans to transfer $\mathbf{3 1 5}$ former long-stay patients to LA or voluntary sector care. However, the pressure to relocate patients meant that plans for a community mental health centre (CMHC) in one of the districts were put into abeyance.

In the district where tasks had been shared between the DHA and LA, one of the nursing homes envisaged in the DHA plan eventually became the subject of joint negotiations between the DHA and a housing association; the DHA agreed that the association should manage the scheme. The DHA also accepted an LA offer to provide up to 50 places in aged persons' homes. In addition, pressure from the RHA resulted in the DHA extending its focus to a more comprehensive range of services: joint discussions then took place on two new CMHCs, respite care, and sheltered workshops.

In North Region, relocation plans took shape after the DHAs established target-numbers to be achieved each year: 20 the first year, then 50 , and so on, until the greater proportion of the 200 'residual' patients had been accounted for. The plans included two LA hostels, 30 placed in LA aged persons' homes, voluntary sector hostels and group homes, and shared and independent accommodation units provided by the LA housing department.

In both regions, a number of plans were amended to provide more support for patients than had originally been envisaged. Staff involved in rehabilitation found that many long-stay patients would not be able to manage independently. As a result, several unstaffed group homes were replaced by staffed homes. This is not to mask the fact, though, that some former patients did move into unstaffed accommodation with peripatetic support.

\section{Aspects of the joint planning process}

As far as the agencies themselves were concerned, the joint planning process was a success in that it resulted in the transfer of patients to LA or voluntary sector care. The problem of discussing 'success' without reference to outcomes for individual patients has already been mentioned. Shortcomings are evident, though, even when the process is considered purely as a planning exercise.

\section{Incrementalism, opportunism, and piecemeal planning}

One important feature of the process in all five districts was its incremental, opportunistic, and piecemeal nature. This was especially true in North Region, where relocation discussions typically centred around the availability of buildings. Moreover, DHA and LA planners admitted that they lacked any clear ideas of their own about the best way forward and they relied heavily on proposals from voluntary organisations.

One of the problems of a piecemeal, opportunistic approach is that there is considerable pressure to meet only the lowest common denominator of need a roof over people's heads - and to provide this as quickly and as cheaply as possible. Other needs are then relegated to second place. Secondly, even where individual projects are valuable in themselves, a piecemeal approach will result in an incomplete range of services. And thirdly, a focus on a 'limited life' service fails to take advantage of a rare opportunity to design a broad new range of services which, in addition to catering for former long-stay patients, will also help to meet people's needs in the future.

\section{Political goals}

In the districts described here, the agencies did not incorporate the relocation question into the planning of a broad range of mental health services. Issues such as CMHCs were either pushed to one side or were introduced later, essentially, as separate developments. This is despite official advice and recommendations from 1974 onwards, which have emphasised the need for a comprehensive joint approach to meeting need (DHSS, 1974; Griffiths, 1988).

One of the reasons for the agencies' limited use of the joint planning machinery lies in the lack of political importance given to broader goals. The DHAs were primarily concerned with closing the hospitals and they used joint planning to further this aim. The provision of a wider range of services simply did not constitute a high-priority objective.

\section{Meeting needs}

Political commitment is also crucial for the way that individual patients' needs are met, whether in terms of responses to identified need, the principles on which services are to be based, or the philosophy underpinning the operation of individual projects.

In neither region were plans substantially based on a detailed appreciation of individual patients' needs. In North Region, detailed assessments were simply not available. In South Region, patients were banded together in broad dependency levels: administrators felt that the sheer size of the task made it impossible to give detailed attention to individual patients' needs or to offer them any real choices.

It has to be acknowledged that hospital-based assessments of people's community care needs can be extremely problematic. Some people may require more support once they leave the sheltered hospital environment than was anticipated; others will display abilities which were not previously evident. What is needed is flexible provision that enables patients to develop their potential for independent 
living whilst receiving individually appropriate levels of support.

\section{Joint planning structures}

The setting in which joint planning was conducted was different in the two regions. In North Region, special joint groups were established to consider mental health issues. In South Region, on the other hand, joint planning initially took place within DHAs' own planning teams, on which LAs and voluntary bodies were represented. In one of the districts, though, a joint planning team was later established where issues could be discussed that did not simply reflect NHS priorities. This reassured LA participants that they were not just subsidiary members or 'sub-contractors'.

Given that outcomes were similar in both regions, it might seem that structures are less important than the ability of individual agencies to work together to reconcile their various goals and interests. However, bitter conflicts in two of the districts in South Region indicate that participation in another agency's planning team is less conducive to genuine collaboration than a joint forum in which no one party can automatically exercise total control.

The precise membership of any joint groups is nevertheless important, both from the point of view of being able to make decisions without constantly referring back to parent agencies, and also to ensure that the planning process is adequately informed about issues such as patients needs and quality of care. In North Region, personality clashes resulted in psychiatrists being excluded from all planning groups for the first two years of relocation discussions: this markedly reduced the amount of information about the services that were required.

Even when medical and nursing staff were involved in discussions, however, they had only a limited impact on outcomes: decisions reflected the interests of those parties who held the resources and hence the power. Managers thus held precedence over medical staff, and DHAs overruled LAs. Voluntary organisations, for their part, were virtually relegated to observer status - as well as being totally excluded from some of the decision-making forums.

\section{Positive spin-offs}

Despite its shortcomings, the joint planning process had positive spin-offs for other aspects of mental health service-planning. In North Region, one district used the joint planning forums as an alternative to its internal mental health planning groups: both a crisis intervention service and new day care services were developed in the joint setting. The other district, which had a reputation for planning in isolation, used the joint groups to raise internal issues that were being considered within the DHA.
In South Region, too, locality planning groups were created in some districts to examine particular local needs. Plans for CMHCs or similar units in all three districts resulted from close collaboration between the DHAs, LAs and voluntary bodies.

\section{What of the future?}

Our work has highlighted:

the need for greater political priority to be given to the goal of jointly designing a comprehensive mental health service

the need for greater clarity about the scope of any joint planning exercise, especially in view of the practical and financial constraints on the agencies involved

the need for a more user-led approach to serviceplanning.

The extent to which these needs might be met depends partly on local agencies themselves and the skill, commitment and expectations that they bring to the planning task. It also depends, though, on the general policy and political environment within which such planning takes place. DHAs and LAs are guided by policy guidelines laid down by central Government, by formal directives about planning structures, and by funding constraints that place limits on the services that can be provided. It is to the national policy context that we now turn.

\section{The national picture}

Recent years have seen a number of official studies on community care and joint planning (Audit Commission, 1986; Griffiths, 1988; DHSS, 1985), culminating in the 1989 White Paper Caring for People (Secretaries of State for Health, 1989). Considerable disquiet has been expressed about the apparent failure of joint planning to provide a satisfactory level of community care and about anomalies in the division of planning between various agencies.

One of the most important features of Caring for People is its emphasis on agencies having clear individual responsibilities and pursuing their own separate tasks. Any interaction between them will no longer be based on the development of joint plans but on planning agreements whose purpose will be to help them achieve their individual goals.

This represents a major departure from previous policy, which has stressed the need for a broader joint approach. However, this article (in common with other studies) has shown that joint planning in a broader sense simply has not happened. 'Successful' joint planning has indeed consisted largely of individual planning agreements rather than more farreaching joint plans: the proposed changes reflect this state of affairs and tacitly acknowledge the practical difficulties that agencies have encountered. 
The change in emphasis nonetheless represents the withdrawal of an ideal goal to which agencies might aspire. The boundary between health and social care needs is far from clearcut: any focus on agencies' discrete responsibilities which does not acknowledge the considerable grey areas between them will constitute a deficient response to meeting need as a whole. The strength of joint planning lies precisely in its focus on the totality of need.

The White Paper does-grudgingly-endorse a limited degree of joint planning: there would be "no impediment", it states, to local agencies producing joint plans. Health authorities will also continue to be able to make grants to LAs and voluntary organisations in respect of patients moving from hospitals to the community. In the case of mental health services, moreover, the White Paper introduces a special grant to be paid by health authorities to LAs, a precondition for which will be the existence of mutually agreed plans. The planning of mental health services will thus call for some joint work, albeit in a fairly limited form.

The fate of joint planning will clearly rest with local agencies themselves. There will no doubt be some who feel that the difficulties and conflicts engendered by joint planning are not worth the time and trouble it takes: they may thus choose to "go it alone" and focus on their own individual tasks (Wistow \& Hardy, 1986). Others, though, will recognise that joint planning has important potential benefits.

The shape of future services will depend a good deal on the extent and nature of any joint planning that takes place. One area in which joint planning could play an important role is in the development of services from the transit bases that we have termed 'limited-life' provision for people who have spent a lifetime in institutions. Various options are open to exploit this source of capital and revenue as the numbers of elderly residents gradually reduce.

Much will also depend on whether housing associations and charitable trusts, the traditional allies of innovative mental health service managers, continue to give a high profile to care in the community.
A Prince of Wales initiative would work wonders for the day care and employment problem, where massive efforts are required if people with mental health difficulties are to be truly integrated into mainstream society. And why should mortgage companies not be involved? After all, that is the way that most of us obtain accommodation for ourselves.

As in the case of all service-planning, what is needed above all is vision. This is especially true where people's needs transcend agency boundaries and where it it not sufficient for agencies to adopt a narrow blinkered approach to the services they provide. In such circumstances joint planning is not merely an optional extra - it is essential.

\section{References}

AUdit Commssion (1986) Making a Reality of Community Care. London: HMSO.

Booth, T. (1981) Collaboration between the health and social services. Policy and Politics, 9, 23-49 and 205-226.

DHSS (1974) Collaboration between Health and Local Authorities. NHS Reorganisation Circular HRC(74)19. London: DHSS.

(1976) Joint Care Planning: Health and Local Authorities. Health Circular HC(76)18. London: DHSS. - (1983) Care in the Community and Joint Finance. Health Circular HC(83)6.London: DHSS.

(1985) Progress in Partmership: Report of the Working Group on Joint Planning. London: DHSS.

GlenNerster, H. with Korman, N. \& MArsLen-WILSON, F. (1983) Planning for Priority Groups. Oxford: Martin Robertson.

GRIFFTHS, R. (1988) Community Care: Agenda for Action. London: HMSO.

Rathwell, T. (1987) Strategic Planning in the Health Sector. London: Croom Helm.

Secretaries of State for Health, Social Security, Wales AND Scotland (1989) Caring for People: Community Care: Agenda in the Next Decade and Beyond. Cm 849. London: HMSO.

WisTow. G. \& HARDY, B. (1986) Transferring care: can financial incentives work? In Health Care UK: an economic, social and policy audit. (eds. A. Harrison and J. Gretton). Hermitge, Berkshire: Policy Journals. 